\title{
Using a Simulation Game Approach to Teach Pull and Push Production System Concepts
}

\author{
Sakun Boon-itt ${ }^{1}$ \\ ${ }^{1}$ Thammasat Business School, Bangkok, Thailand \\ Correspondence: Sakun Boon-itt, Thamasat Business School, 2 Prachan, Rd. Pranakorn Bangkok 10200, \\ Thailand. Tel: 66-2-613-2201.E-mail: sboonitt@tu.ac.th
}

Received: March 6, 2012

doi:10.5539/emr.v1n1p110
Accepted: April 9, $2012 \quad$ Published: May 1, 2012

URL: http://dx.doi.org/10.5539/emr.v1n1p110

\begin{abstract}
The main objective when teaching the Production and Operations Management (POM) course is to provide students with the understanding and ability to apply theories and principles to real-world production. However, the teaching of this course is clearly different from some other courses in which students can apply theories to laboratory simulations; for example, the Plant Design course. This paper proposes game simulation for the POM course on production using Pull system and Push system, assuming situations of television production applied from Hongyi Sun's method. The main materials are white paper, color pens, and production order cards. The main purpose was to provide students with a clear and factual visualization of overall production planning systems. The game simulation was tested with students of the POM course in the Industrial Management and Operations Program, Thammasart University. This game simulation study was compared with normal lecturing. It was found that students were mostly satisfied with the simulation and found it to be an interesting approach, providing the opportunity for problem-solving, creating a better understanding of both production-planning principles.
\end{abstract}

Keywords: game simulation, production and operations management, teaching

\section{Introduction}

Teaching the concepts underlying a production planning and control is a difficult task. Many students have very little technical experiences to which they can relate both business and technical aspects together. They may have acquired business experience, but many of them have only limited understanding of the operational or technical aspects. Modern educational games are considered to be effective tools in management education, using action instead of explanation to provide an interactive decision-making context (Kebritchi and Hirumi, 2008). A number of authors have suggested the use of simulations game as an innovative pedagogical approach to teach business concepts (Aldrich, 2003; Prensky, 2001; Anderson and Lawton, 2009). Simulation games replicate the complexity of a real-life environment, giving the students experience with a particular phenomenon. For instance, Cronan et al. (2012) compared objective measures and perceptions of cognitive learning in an ERP simulation game and found the different results between using game and traditional training.

POM is one of the fundamental courses in the Management faculty, but most students who take the course do not demonstrate much interest in its content. One main reason is that students do not see the importance of the content because it is different from other Business Administration courses, such as Accounting or Finance, where students can clearly understand the application of the content to their future career. Another reason is that the content is very complex as a result of the interrelationships among the three main parts: Engineering, such as Processing, Production and Machine Technology; Resource Management, such as Planning, and Project and Capital Management, as well as Resource and Quality Management; and Operations Research as a tool for Production Management.

In other words, the course in POM is difficult to teach effectively in a purely theoretical setting. From teaching experience it can be observed that the course is not very popular among Business Administration students because its content mainly relates to Engineering and Operations Research. Students need some way to directly experience the issues related to operating a production system. To solve this problem it is important to encourage students to engage with and understand the content, especially Engineering Processes and Operations Research, 
areas in which Business Administration students do not have basic knowledge and may be unable to visualize while studying in class. One solution is to use games as teaching materials. Ment (1983) defined a game as a simulation that learners can relate to a real situation by assuming roles and being involved in decision-making. Science and Engineering courses use games in the form of laboratory experiments, which help students to understand the subject and increase their interest.

In the previous studies, simulation games have also been used in the Production and Operations Management (POM) course. The interest in using simulation games as a teaching method on the POM course is based on the following reasons. Firstly, the game simulation provides students with direct experience of the issues involved in an operating system (Sterman, 1989b; Lewis and Maylor, 2008). Secondly, the game simulation creates a learning environment, with assistance from the lecturer, in which students must make decisions and think for themselves (Agogino and Wood, 1984). For example, Sun (1998) proposed game simulations as a balance between theory and practice. Lastly, game simulation leads to the assessment of students, especially their understanding of how to apply the content to the real business world (Anderson and Morrice, 2000).

POM education employs a wide variety of games, including:

- The Stationary Beer Game (Sterman, 1984), which is a Supply Chain Management game simulation. Subsequently, Jacob (2000) developed this game to be played through the Internet.

- Supply Chain Management software, developed by CAPS Logistics and Numtrix, which has been applied for use as a teaching material for Production and Operations Management at Georgia Institute of Technology.

- Heineke and Meile (1995) provide a copy of student handouts, instructional tips, suggested time frames for game completion and questions for discussion to accompany each game in production and operations management.

- The Simens Brief Case Supply Chain game simulators (Simens 1995a, 1995b).

- Production planning and control game simulation developed through the MS Visual Basic program (Kanazawa and Masumoto, 2000).

- Ammar and Wright (1999) described eight games that have been effectively used to complement the traditional theoretical presentation in the POM course: Lego My Simplex, Balancing Planes, The Distribution Game, The Cups Game, The Beer Game, Red Bead Experiment, Goldratt Game, and ABC's Manufacturing.

The objective of this paper is to apply a simulation game approach to teaching two different production planning systems (i.e. Pull system and Push system) so that students can develop a better understanding and apply the ideas in the real world. This game simulation uses some principles from Sun (1998), who invented games for production planning and control. The first part of this paper summarizes general ideas about both production planning systems. The second part explains the designs and characteristics of the games in relation to Production Planning and Resource Management, and in particular the use of the game with POM students. The final part presents the learning experiences and opinions of the students who experimented with the game simulation.

\section{Description of the Pull and Push Production Systems}

The main objective of the game simulation for production planning systems is to compare the difference between Pull and Push production systems, often referred to as Just-in-Time (JIT) and Material Requirements Planning (MRP), respectively. JIT is called the Pull system because production planning takes place according to customers' real needs, while the Push system or MRP occurs based on the forecast of needs and specified delivery time. In other words, all production planning information in JIT occurs based on customers' needs, transferred backward to each workstation for production.

The terms push and pull refer to the means for releasing jobs into the production facility. In a push system, a job is started on a start date that is computed by subtracting an established lead time from the date that material is required. Historically, Material Requirements Planning (MRP) has been the most widely spread computerized planning system for job shop and batch manufacturing systems (Orlicky, 1974). In a MRP system component and raw material requirements are calculated by time-phased explosion of the master production schedule requirements, using bill of material (BOM) and inventory records. Detailed shop scheduling is performed by the shop floor control function, as part of the more extended MRPII systems.

Although MRP is a well developed data management systems, it has not lived up to expectations for increased system performance (Anderson et al, 1982). Thus, much attention has been focused on pull system referred to 
Just-in-Time (JIT) system. In this demand driven control, work is pulled through the system which the succeeding stage demand and withdraws items from the preceding stage, based on the rate at which the succeeding stage consumes items (Deleersnyder et al., 1989; Sharma and Agrawal, 2009). All operations then perform work only to replenish outgoing stock (Spearman and Zazanis, 1992). In practice, work is coordinated by using a signal (Kanban) represented by a card or sign. Hall (1993) provided a good explanation of how Kanban works. He suggests that the variability reduction found in pull systems is extremely important to overall systems effectiveness. Karmarkar (1986) points out that the number of cards (Kanbans) in the system creates an upper limit on work-in-process (WIP).

Figure 1 illustrates material flows, indicated by solid arrows, and information flows, indicated by dotted arrows. In part (a), the material and information flows are in opposite directions. This is the Pull system or JIT because workstation 1 will only commence production if workstation 2 has a requirement first. In part (b), the material and information flows are in the same direction. This is the Push system or MRP since workstation 1 will produce based on the order received without knowing whether workstation 2 has a requirement or not.

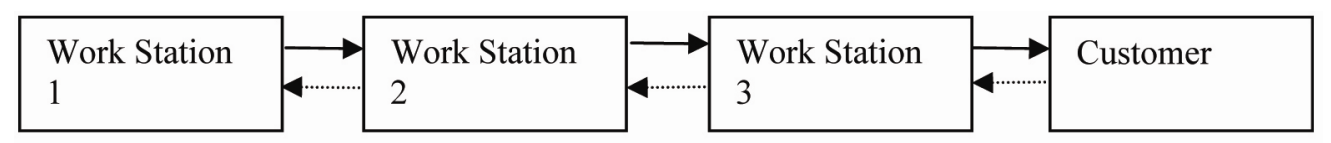

(a) Pull system

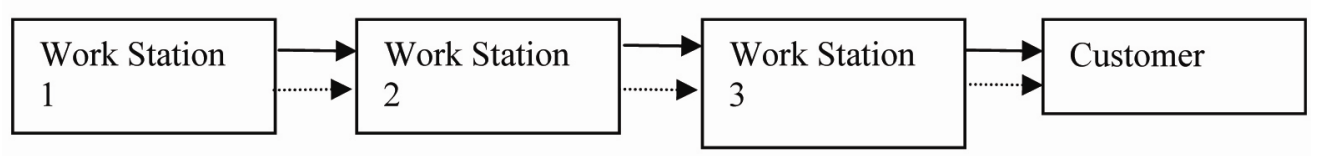

(b) Push system

Figure 1. Material and information flows in pull and push systems

One important principle of JIT production is KANBAN, which means label or sign in Japanese, used as a production control for volume in the production line. Quantities of KANBAN labels are based upon customer needs and specified safety stock. The benefit of applying the KANBAN principle is that quantities of work in progress (WIP) and inventory will be controlled during production.

Figure 2 illustrates the area between the Pull system (MRP inflow) and outflow and the KANBAN system (JIT inflow) and outflow. The area between these inflow and outflow lines indicates inventory quantity. The inventory (area A) for the KANBAN system is lower than that for the Push system (area B), while the area between the lines is higher and tends to increase.

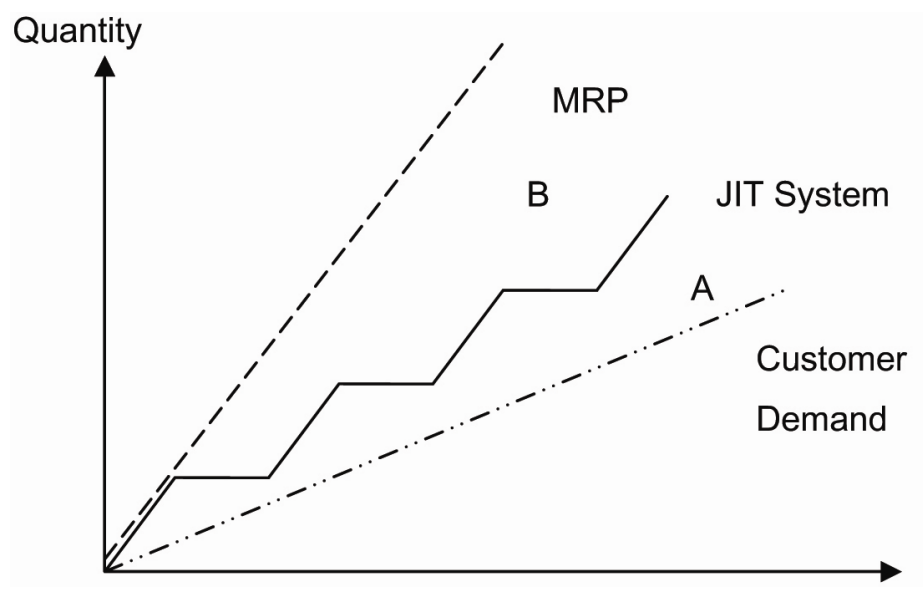

Figure 2. Quantities of WIP and inventory for pull and push systems

The main objective of this game simulation is to compare JIT and MRP production. The important indicators used for comparison are customer waiting time, WIP, inventory stock, and production volume/time. 


\section{The Simulation Game Process and Characteristics}

One important issue in designing games for POM is that Production Management game simulation is much more complex than General Management game simulation. This is because Production Management comprises both Engineering processes and Resource Management components. Therefore, the current trend in Production Management game simulation is computer simulations (Garetti and Taisch, 1995) or toy block building formats (Johanson and Mikkeisen, 1995), where the cost of developing the game simulation is high and the playing method is more complex than general games. Hence, the game designer must consider the cost and ease of use of each game simulation.

The proposed game simulation is for color television production, with several components such as products, producers, production processes, marketing, and production resources (e.g., personnel).

\subsection{Products, Customers, and Marketing Information}

The products are two color television models, AA and BB. Each model comes in two colors, red and black. Therefore, there are four types of production: AA in black, AA in red, BB in black and BB in red. The quantity of each model required can be 1,2 , or 3 sets. The marketing information is shown in the following table.

Table 1. Marketing information

\begin{tabular}{ll}
\hline Production Model & Quantity \\
\hline AA, Black & $1,2,3$ \\
AA, Red & $1,2,3$ \\
BB, Black & $1,2,3$ \\
BB, Red & $1,2,3$ \\
\hline
\end{tabular}

From Table 1, the probability of obtaining any one model without consideration of production volume is $25 \%$ ( 3 from 12 cards). To exhibit the uses of this marketing information, the purchase order card will provide information such as model, color, and quantity needed (maximum 3 sets). As shown in Figure 3, 12 total purchase cards $(3 \times 4)$ will be used to find marketing information.

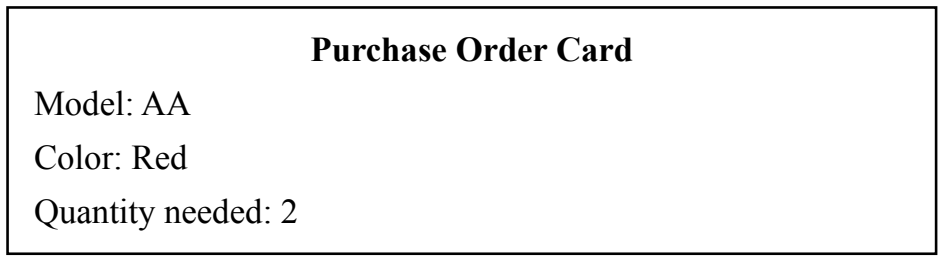

Figure 3. Purchase order card

When the game starts, two players are customers, one of whom randomly selects a purchase order card from the 12. When the other player receives the purchase order card, they record information on the purchase order, as shown in Figure 4: purchasing sequence, model, color, quantity needed, ordering time, and product receiving time. These times will be used for calculating waiting time; for example, the ordering time is 8:02am, the receiving time according to the purchase order is 8:07 am, so the total waiting time is 5 minutes.

\begin{tabular}{|lc|}
\hline Order Sequence & \multicolumn{2}{c|}{1} \\
Model & AA \\
Color & Red \\
Quantity needed & \multicolumn{2}{c|}{2} \\
Ordering time & $8: 02$ \\
Product receiving time & $8: 07$ \\
\hline
\end{tabular}

Figure 4. Purchase order 


\subsection{Production Processes and Operator}

The production processes in this game simulation comprise five workstations, numbered 1 to 5 . The transfer between stations is enacted between the players at each station. For each model, AA and BB, the game designer can specify their own designs with equal workstations. One player is required for each workstation.

Workstation 1 prepares raw materials using one piece of A4 paper; workstation 2 is television assembly; workstation 3 is monitor assembly; workstation 4 is antenna and button assembly; and workstation 5 is stand assembly and product distribution. All players have red and black pens as tools to draw a picture for producing televisions in each color.

\subsection{Production Resources and Operators}

Apart from the operators at each of the five workstations, one player is assigned as Production Manager to control, plan, and monitor the production under the MRP system. Two Production Engineers are assigned to measure WIP, production volume, and inventory stock after production every 30 seconds. However, the number of operators assigned will depend upon the numbers of players.

\section{Application of the Game Simulation to a Real Situation}

This game simulation was tested with 30 students, divided into three groups, in the POM class taught at the Faculty of Commerce and Accountancy, Thammasart University. Most of the students did not have knowledge of Production Management, especially JIT and MRP production planning systems. Before using this game simulation, students studied theories of both production planning systems in order to develop a better understanding while playing the game. Moreover, the following assessment questions were set for the students in order to provide them with a framework for feedback and suggestions:

- What is your opinion of this game simulation as a teaching material?

- What are the advantages and disadvantages of using this game simulation as a teaching material?

- How should this game simulation be developed?

The game began at each production planning system in turn. During the game, Production Engineers and customers recorded important information.

\subsection{Game Simulation for the MRP Planning System}

Under the MRP planning system, the production manager plans production by using marketing information about the model, color, and production quantity, based on the requirement of producing the four models. The Production Manager provides production planning from workstation 1 to workstation 5. Production orders are placed every 30 seconds. The customer randomly chooses the requirement by taking a purchase order card, as shown in Figure 3, every 30 seconds.

Total playing time was 15 minutes. The results were as follows: production planning of 45 televisions, total customer purchase of 21 televisions, and real production of 32 televisions. Therefore, the production volume was 2.13 televisions per minute, with 11 televisions in inventory stock. The average waiting time for the customer was 2 minutes, and the waiting time at the beginning would be 3 minutes above the average waiting time.

\subsection{Game Simulation for the JIT Planning System}

After the MRP planning system, players were assigned JIT production planning, in which the planning mainly depends upon customer needs. The customer randomly picks a purchase order card, as shown in Figure 3, every 30 seconds. Then, the customer fills in a purchase order card, as shown in Figure 4, used as a KANBAN card to control WIP and the inventory. The KANBAN card is then sent backwards from workstation 5 to workstation 1 so that the players at each station receive the necessary information to produce based on the purchase order. The total playing time was 15 minutes, the same as the MRP simulation. The result for average customer waiting time was 0.9 minutes, the same as production waiting time; the inventory stock and WIP were at 0 , and production volume was 1.98 televisions per minute.

Comparing the production planning systems, the MRP system produced more televisions, but the JIT system had less inventory stock and a lower customer waiting time. Moreover, customers received better quality products under the JIT system since production was not hurried, unlike the MRP system, which had to hurry to meet the Push production planning. Likewise, production under the JIT system was more flexible and provided better responses to changing customer needs. 


\section{The Learning Experiences and Opinions of the Students}

This section reviews the main lesson learned from this pedagogical experience. This section discusses the learning process of the students, the evaluation and improvement to the simulation game based on the students' comments.

\subsection{Evaluation of the students}

After the game simulation was complete, all of the students in the group discussed their responses to the questions received at the beginning so that they could provide appropriate suggestions. Feedback from the student has indicated an improved level of appreciation of the complexity and the difference of the pull and push production systems. A typical reaction from students is that although they have considerable knowledge about the concept of pull and push systems (JIT and MRP), the difficulties of the difference between these two concepts were not appreciated. In particular, students felt that they participated more in production. For example, the Production Manager felt that the inventory stock or waiting time depended upon the planner's decision. In addition, by using this game simulation, students could use visualization and touch to better understand and memorize the principles compared to learning by heart. However, there were also some suggestions of improvements from the students:

- The game simulation should expand its scope to include Supply Chain Management and Inventory Management.

- Production using picture drawing is too simple, which made for an unrealistic production time. Production should be paper folding or block building to make it more realistic.

- Everyone should alternate taking responsibility for the different roles in order to learn about the entire system.

- The time required to be familiar with the game simulation is very important, therefore more time should be allocated.

- Sales staff should be included in order to receive purchase orders from the customer instead of the customer giving them directly to Production.

\section{Conclusion}

The application of game simulation to the teaching of the Production and Operations course increases student confidence as theories can be visualized within the context of their future application in the real world when used in conjunction with traditional lectures. When the students are faced with any of these applications in the future, this in-class game has provided them with hands-on experience of Pull and Push production systems. This game-based approach holds several advantages over existing lecture-based study. In comparison, it has a very visual nature, is simple and fun to play, allows for collaborative learning and provides almost immediate feedback to students about the lessons we could teach. The results show that students will embrace the use of the game was both a useful test subjects felt that playing the game was both a useful lesson and an enjoyable experience. In the meantime, the pressure upon lecturers will be relieved, since the application of the game simulation will motivate students and make studying more real-world lessons. In addition, most students felt that it would be a valuable addition to a production and operations course's curriculum.

Based on early feedback and lessons learned from testing this game, a new version can be developed in many directions, for example by including Supply Chain Management and Inventory Management, or computer simulation for results interpretation and analysis. Current government policy of learner-centric teaching means that the lecturer is responsible for suggesting things that the learner should know, and the learner is also responsible for searching for solutions. The game simulation may not be the best solution for this policy, but it is a stimulus towards more learner-centric teaching.

\section{References}

Agogino, A. M., \& Wood, W. H. (1994). The Synthesis Coalition: Information Technologies Enabling a Paradigm Shief in Engineering Education. Keynote talk, in Hyper-Media in Vassa' 94 (pp. 3-10). Proceeding of the Conference on Computers and Hypermedia in Engineering Education.

Ammar, S., \& Wright, R. (1999). Experiential Learning Activities in Operations Management. International Transaction in Operational Research, 6, 183-197. http://dx.doi.org/10.1111/j.1475-3995.1999.tb00150.x 
Anderson, E. G., \& Morrice, D. J. (2000). A Simulation Game for Teaching Service-oriented Supply Chain Management: Does Information Sharing Help Managers with Service Capacity Decision?. Production and Operations Management, 9(1), 40-55. http://dx.doi.org/10.1111/j.1937-5956.2000.tb00322.x

Anderson, P. H., \& Lawton, L. (2009). Business Simulation and Cognitive Learning: Developments, Desires, and Future Directions. Simulation and Gaming, 40(2), 193-216. http://dx.doi.org/10.1177/10468781083216 24

Cronan, T. P., Leger, P., Robert, J., \& Babin, G. (2012). Comparing Objective Measures and Perceptions of Cognitive Learning in ERP Simulation Game: A Research Note. Simulation and Gaming, 43(1), 234-245.

Deleersnyder, J., Hodgson, T. J., Muller, H., \& O’Grady, P. J. (1989). Kanban Controlled Pull Systems: An Analytic Approach. Management Science, 35(9), 1079-1091. http://dx.doi.org/10.1287/mnsc.35.9.1079

Garetti, M., \& Taisch. (1995). Overview of the FMS Design Game. In Riis, J.O. (Ed), Simulation and Learning in Production Management (pp.43-61). Chapman \& Hill, London.

Hall, R. W. (1983). Zero Inventories. Dow Jones-Irwin, Homewood, IL, USA.

Heineke, J., \& Meile, L. (1995). Games and exercises for operations management: hands-on learning activities for basic concepts and tools. Englewood Cliffs, NJ: Prentice-Hall.

Jacob, F. R. (2000). Playing the Beer Distribution Game Over the Internet. Production and Operations Management, 9(1), 31-39. http://dx.doi.org/10.1111/j.1937-5956.2000.tb00321.x

Johansen, J., \& Mikkelsen, H. (1995). The Lego Truck Game: A Game for Production Control. In Riis, J.O. (Ed), Simulation and Learning in Production Management (pp. 127-133). Chapman \& Hill, London.

Kanazawa \& Masumoto. (2000). A System Flow Analysis in Production Management. Teaching Notes, Training Course in Production Management Information System (PROMIS), Asian Productivity Organization, Japan.

Karmarar, U. S. (1986). Kanban Systems. Working Paper Series No. QM8612, Center for Manufacturing and Operations Management, The Graduate School of Management, University of Rochester, Rochester, NY.

Kebritchi, M., \& Hirumi, A. (2008). Examining the Pedagogical Foundations of Modern Educational Computer Games. International Journal of Production Economics, 51, 1729-1743.

Lewis, M. A., \& Maylor, H. R. (1989). Game Playing and Operations Management Education. International Journal of Production Economics, 105, 134-149. http://dx.doi.org/10.1016/j.ijpe.2006.02.009

Ment, M. V. (1983). The Effective use of Role Play, Kogan Page, Nichols Publishing Company, New York, NY.

Sharma, S., \& Agrawal, N. (2009). Selection of a Pull Production Control Policy Under Different Demand Situations for a Manufacturing Systems by AHP Algorithm. Computers and Operations Research, 36(5), 1622-1632. http://dx.doi.org/10.1016/j.cor.2008.03.006

Siemans Corporation. (1995b). Brief Case Instructor's Manual. Iselin, NJ.

Siemans Corporation. (1995a). Brief Case Game Participant's Binder. Iselin, NJ.

Spearman, M. L., \& Zazani, M. A. (1992). Push and Pull Production Systems: Issues and Comparison. Operations Research, 40(3), 521- 532. http://dx.doi.org/10.1287/opre.40.3.521

Sterman, J. D. (1984). Instructions for Running the Beer Game (D-3679). Sloan School of Management, MIT.

Sterman, J. D. (1989b). Modeling Managerial Behavior: Misperceptions of Feedback in a Dynamic Decision Making Experiment. Management Science, 35(1), 321-339. http://dx.doi.org/10.1287/mnsc.35.3.321

Sun, H. (1998). A Game for the Education and Training of Production/Operations Management. Education Training, 40(9), 411-416. http://dx.doi.org/10.1108/00400919810247212 